\title{
Neovanguardias en la poesía del cono sur: los 70 y sus alrededores*
}

\author{
Neo-avant-gardes in Southern cone poetry: the 70's and around \\ Oscar Galindo V. \\ Universidad Austral de Chile, Instituto de Lingüística y Literatura, Valdivia, Chile, \\ e-mail: ogalindo@uach.cl
}

Este artículo analiza la producción poética neovanguardista en el cono sur hispanoamericano (Argentina, Chile y Perú), tomando como eje la producción de la década del 70. Es en este momento que se produce una reemergencia neovanguardista que establece una ruptura respecto del coloquialismo característico de la promoción anterior. Así aparecen en el sistema literario movimientos y productos que reprocesan el gesto de las vanguardias históricas, provocando no sólo un quiebre en las disciplinas artísticas, sino también expresiones heterogéneas y mutantes, que directa u obliteradamente expresan el gesto político de su ruptura.

Palabras clave: vanguardia, neovanguardia, heterogeneidad, mutaciones, migraciones.

This article analyzes the neo-avant-garde poetry production in the Spanish-American Southern cone (Argentina, Chile, and Peru), based on the production of the 1970's. It was at this moment that a neo-avant-garde re emergence occurred, and which ruptured from the colloquialism typical of the previous promotion. Thus, several movements and products appeared in the literary system, re-processing the gestures of the historical avant-gardes, provoking not only a breakdown in the artistic disciplines, but also heterogeneous expressions and mutants, which direct or obliteratingly expressed the political gesture of their rupture.

Key words: avant-garde, neo-avant-garde, heterogeneity, mutations, migrations.

A diferencia tal vez de las expresiones más radicales de las vanguardias europeas, las vanguardias hispanoamericanas, con excepciones, nunca fueron plenamente antiartísticas, más bien lo que hicieron fue aprovechar los recursos que el nuevo repertorio les ofrecía para rescatar el arte, atravesado ahora por un gesto metacrítico. La poesía hispanoamericana muestra este derrotero desde Huidobro, pasando por Borges y Vallejo, hasta la así llamada segunda vanguardia. Peter Bürger (1987) ha

\footnotetext{
* Este artículo forma parte del proyecto de investigación Fondecyt 1070208 "Migraciones y mutaciones en la poesía hispanoamericana actual del cono sur (Argentina, Chile, Perú. 1960-2000)”. Investigador responsable: Oscar Galindo V.; coinvestigadora: Claudia Rodríguez M.

Una primera versión fue leída en las VIII Jornadas Andinas de Literatura Latinoamericana (JALLA) 2008, Universidad de Chile, 11 al 15 de agosto.
} 
llamado fase postvanguardista al arte que se puede caracterizar porque la categoría de obra ha sido restaurada utilizando procedimientos ideados con intención antiartística por la vanguardia para fines artísticos. Ejemplos provenientes de las artes visuales y la poesía comienzan a desarrollarse consecutiva y sucesivamente en Latinoamérica a partir de los años 60 como un modo de cuestionar los modelos de representación: Diagonal Cero, Tucumán Arde, Nosferatu y El Lagrimal Trifulca en Argentina, Hora Zero en Perú, El Techo de la Ballena en Venezuela, el Nadaísmo en Colombia, CADA en Chile, aparecen en la escena no sólo como un quiebre en las disciplinas provocando expresiones heterogéneas y mutantes, sino también que directa u obliteradamente expresan el gesto político de su ruptura. Para estas expresiones en general se ha venido imponiendo el uso de la denominación "neovanguardistas"1.

El horizonte de preferencias de la poesía hispanoamericana de las últimas décadas se caracteriza por un proceso de mutaciones y migraciones interdisciplinarias que lo han afectado especialmente desde los años 60 en adelante (Carrasco 2002; Galindo 2002 , 2004), aun cuando antecedentes se encontraban en la propia primera vanguardia. Los 60 dan lugar a un tipo de textualidad ambivalente, que cuestiona las dimensiones taxonómicas, genéricas y disciplinarias convencionales. Con la generación de "los nuevos" en Perú (Antonio Cisneros, Rodolfo Hinostroza, Mirko Lauer) ingresan a la poesía hispanoamericana los aportes de la tradición anglosajona y una preocupación sociológica, histórica y antropológica que atraviesa el discurso poético en busca de nuevos mecanismos de representación de lo real $^{2}$. En el caso de la poesía argentina de los 60 los críticos suelen coincidir en su marcada tendencia al realismo, a las preocupaciones sociopolíticas (Andrés 1969; Fonderbrider 2006, 2008), pero también supone abrirse a la cultura de los mass media, el cómic, la publicidad (Salas 1975). Fundamentales por su aporte renovador fueron El saboteador arrepentido (1955) y Al público (1957) de Leonidas Lamborghini, poeta que será rescatado en los 70 por su carácter renovador y radicalmente experimental (Friedemberg 1999), y Violín y otras cuestiones (1956) de Juan Gelman. En Chile la renovación y revisión de la vanguardia se inicia con la publicación en el año 54 de Poemas y antipoemas de Nicanor Parra; el 63 se publica otro libro fundamental: La pieza oscura de Enrique Lihn; también en esta década aparecen los primeros libros de Oscar Hahn y Gonzalo Millán y al iniciarse los 70 los primeros poemas de Juan Luis Martínez y Raúl Zurita, aunque su poesía se desarrolla con propiedad a partir de fines de esta década.

\footnotetext{
${ }^{1}$ La denominación neovanguardia se ha utilizado para denominar al Grupo 63 italiano, liderado por el poeta Edoardo Sanguineti, e integrado por Umberto Eco, Nani Balestrini, entre otros. Sanguineti explora en las relaciones ideología lenguaje, por medio de recursos como el plurilingüismo, el non sense y la descontextualización de los contenidos culturales. También ha servido para referirse a la Noveau Roman integrada por los novelistas Robbe-Grillet y Claude Simon (Calinescu 2002). En Estados Unidos Adrian Henry, Roger Mcgough y Brian Patten, Jack Kerouac y Allan Ginsberg, desde diversos escenarios contribuyen al desarrollo de una poesía neovanguardista.

2 Antonio Cisneros, por ejemplo, en la histórica antología Los Nuevos (1967) señala: "Olvidaba mencionar la importancia que en nuestros días tiene el aumento de estudiantes y estudiosos de las Ciencias Sociales, el acercamiento antropológico a la realidad y no el puro apriorismo sobre ella; y cómo los pálidos hombres de Letras y Filosofía somos desplazados por aquellas funciones más actuales de las llamadas Ciencias del Espíritu" (1967: 15). La antología, preparada por L. Ceballos Mesones y considerada fundadora de este nuevo paradigma, incluye, además de la "Presentación" de Ceballos, textos de Antonio Cisneros, Carlos Henderson, Rodolfo Hinostroza, Mirko Lauer, Marco Martos y Julio Ortega, junto a una breve presentación o autopresentación de cada poeta y respuestas a un cuestionario de carácter metapoético.
} 


\section{LOS 70: VANGUARDIA, EXPERIMENTACIÓN, VIDA}

1. La poesía peruana se ha constituido en uno de los sistemas poéticos más heterogéneos y abiertos de la literatura hispanoamericana. James Higgins afirma que en la historia de la poesía peruana "hay cierto paralelo entre la década del 70 y los años 20" (1993: 191), en cuanto al origen provinciano y humilde de los principales poetas. Es cierto, pero más cierto es el paralelismo si se piensa en la voluntad experimental que reemerge en los 70, como emergió en la segunda década del XX. De los grupos que se formaron en los setenta ${ }^{3}$, Movimiento Hora Zero (1970-1973) constituye un fenómeno equivalente a CADA en Chile o los neobarrocos en Argentina. Hora Zero fue liderado por Jorge Pimentel y Juan Ramírez Ruiz, además de Mario Luna, Jorge Nájar, Julio Polar y José Carlos Rodríguez, todos ellos fundadores del grupo. Se integran posteriormente poetas de la relevancia de Tulio Mora, Enrique Verástegui y Carmen Ollé. Se caracterizó por su afán polémico y su radical contenido político marxista latinoamericano, al menos como se desprende del manifiesto del primer número de la revista: "Queremos cambios profundos, conscientes de que lo que viene es irreversible porque el curso de la historia es incontenible y América Latina y los países del tercer mundo se encaminan hacia su total liberación"4. Sus antecedentes no estaban en la poesía peruana de los 60 ya instalada (Cisneros especialmente), sino en César Vallejo, en Javier Heraud y Eduardo Tello, ambos muertos tempranamente en la guerrilla, en la generación beat norteamericana y en los exterioristas nicaragüenses. Sin embargo, más allá de la búsqueda de una poesía libre, abierta y plural en que ingresaba todo tipo de recursos y ritmos, su preferencia por escenarios y lenguajes cotidianos remitía de modo oblicuo a la generación que les antecedía.

Vitalismo y poema total. El movimiento resitúa en el contexto latinoamericano algunos de los principios fundamentales de las vanguardias históricas: voluntad de ruptura, vinculación entre poesía y política, recuperación del proyecto arte-vida, actitud iconoclasta, experimentalismo textual. Su singularidad latinoamericana y peruana es

\footnotetext{
${ }^{3}$ César Toro Montalvo destaca que la poesía peruana de estos años "asumió con todos sus riesgos los roles de la vanguardia" (1991: 12). Movimientos universitarios, cuyos focos de irradiación serían las universidades Villarreal, Católica, Garcilaso, Cancuta y Lima, más que la de San Marcos. El complejo panorama político está marcado por el golpe militar de Velasco (1968-75) y luego la reinstalación democrática de Belaúnde Terry. Además de Hora Zero, Toro destaca el rol de Estación reunida (1967-68), integrado por Tulio Mora, Elqui Burgos, José Rosas Ribeyro y Patrick Rojas; el Grupo Gleba (Humberto Pinedo, Jorge Ovidio Vega, Farfán Escaffi, Minaya Chea, Ricardo Falla); el Movimiento de Poetas Mágicos del Perú (Omar Aramayo, C.T.M., Sergio Castillo, Roger Contreras, Martín Fierro, Susana Baca, Gerardo García Rosales y Beatriz M.); y La Sagrada Familia (Edgar O’Hara, Guillermo Niño de Guzmán, Enrique Sánchez Hernaní, Luis Alberto Castillo y Roger Santibáñez). De este enorme grupo rescata como integrantes persistentes de esta generación a Pimentel, Ramírez Ruiz, Toro Montalvo, Aramayo, Watanabe, Verástegui, Morales, Armijos, Zúñiga, Ollé, Nájar, Sánchez León, Rosas Ribeyro, Málaga, Rupay y Mora (1991: 16-19).

${ }^{4}$ Más allá de consideraciones respecto a qué hechos son los más apropiados para tener en cuenta al momento de fijar bajo una nominación de temporalidad el surgimiento de una nueva «Generación» de autores (si los específicamente políticos o los específicamente literarios, si 1968 o 1970), un hecho claro es la relación histórica y mediación existente entre el velasquismo y «Hora Zero». En ese sentido, este grupo puede verse como parte de la ola antioligárquica en la que se generó el gobierno de Velasco. Su manifestación en el campo poético, su estallido en el plano de la poesía fue «Hora Zero». Como escribe David Wood en su libro De sabor nacional. El impacto de la cultura popular en el Perú: «La emergencia de este grupo [de poetas provincianos aparecidos a finales de la década de 1960] coincidió por supuesto con la toma del poder del régimen del general Velasco y, dentro de ese ambiente sociopolítico, se formó "Hora Zero"» (de Lima 2009).
} 
evidente tanto en sus manifiestos como en sus textos y obedece más allá de su voluntad de romper con la tradición poética a una corriente que alimenta la búsqueda de una expresión latinoamericanista de raigambre marxista en el contexto postrevolución cubana, que incorpora la dimensión popular y marginal de las culturas latinoamericanas. Se trata de un realismo de vanguardia que articula un discurso de alta complejidad cultural con los lenguajes populares y marginales; la integración de diversos géneros y disciplinas en un macrotexto complejo y fuertemente experimental: poesía, ensayo, ciencias, imágenes, mass media, entre otros; la exploración en una nueva subjetividad polifónica y dramática, que integra registros culteranos, míticos y urbanos.

Juan Ramírez Ruiz (1946-2007), coautor junto a Jorge Pimentel (1944) de "Palabras urgentes", el manifiesto inicial de Hora Zero, y del ensayo "El poema integral" que establece los fundamentos principales de la nueva poética, es autor de una obra escasa pero innovadora y vital: Un par de vueltas por la realidad (1971), Vida perpetua (1978) y luego de un largo silencio de Las armas molidas (1996). También en los primeros años de la década del 70 Jorge Pimentel publica Kenacort y valium 10 (1970) y Ave soul (1973), y Enrique Verástegui En los extramuros del mundo (1971). Los trabajos de estos autores son intentos relevantes por escribir libros totalizadores, interdisciplinarios. La actitud de Hora Zero finalmente muestra una dimensión vitalista de raigambre neorromántica como ocurre con movimientos contemporáneos en Argentina o Chile y se proyecta al grupo Kloaka en la década de los 80, integrado por poetas como Roger Santiváñez, Dalmacia Ruiz Rosas, Mariela Dreyfus y Domingo de Ramos.

Un caso ejemplar de exploración, y no de experimentación, pues no se trata de una poesía experimental, es la propuesta del peruano Enrique Verástegui (1950), autor, entre otros textos, de En los extramuros del mundo (1971), Praxis, asalto y destrucción del infierno (1980), Leonardo (1988), los dos volúmenes de Angelus novus (1989, 1990) y Monte goce (1991). Desde el ya célebre "Salmo" de En los extramuros del mundo, que reescribe de manera singular secciones de "Aullido" de Allen Ginsberg, se advierte la voluntad crítica e indagatoria de Verástegui: "Yo vi caminar por calles de Lima a hombres y mujeres carcomidos por la neurosis, / hombres y mujeres de cemento pegados al cemento aletargados confundidos y riéndose de todo". Su poesía luego se vuelve totalizadora, tras la búsqueda del "poema integral" como indica el manifiesto horazerista. Leonardo es un texto disciplinarmente heterogéneo y mutante en el que introduce una sucesión de registros pictóricos (con referencias a Benjamin), musicales (a través de pentagramas), plásticos, literarios y lingüísticos. Pero es, además de una referencia histórica a los artistas renacentistas tras la búsqueda de la armonía total, una exploración en la identidad peruana e hispanoamericana. El poema "Libro del maestro en mecánica de tornos" es una explicación de la migrancia del campo a las ciudades, verdadera obsesión de la contemporaneidad peruana: "el mundo que ahora tendrás no será el mundo que conociste" (1938: 39). La preocupación con la condición peruana se complementa con poemas dedicados a González Prada, Vallejo y Eguren, integrándose él mismo a una tradición dialógica de signo actual. La angustia por la explicación del universo se vuelve obsesivamente metacrítica en textos como "Estudios filosófico-matemáticos para la aplicación de computadores manuales a la escritura poética", ambigua búsqueda del poema total ya no por medio de las 
tradicionales experiencias de conocimiento de lo absoluto, sino de la tecnología: "El mundo no es más que un alfabeto y el alfabeto puede ser transcrito en valores matemáticos" (1988: 104).

Los notables resultados poéticos de estas búsquedas metalingüísticas se pueden advertir en el siguiente fragmento:

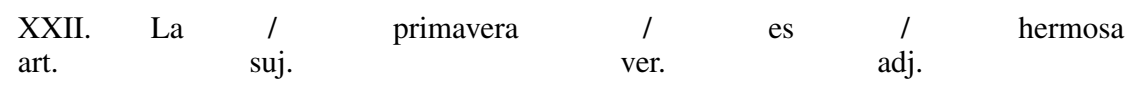

-Qué significa? ¿La multiplicación de un artículo + un sustantivo + un verbo + un adjetivo -que produce?

Si multiplico $1 \times 2 \times 5 \times 3$ llego a un punto:

Sale 30 (pero ¿cómo sé que: la primavera es Hermosa?)

XXII. Esta es una dirección que viene de Spinoza y Prosigue con Deleuze: $1^{\circ}$ resultado

XXIV. ¿Pero si al multiplicar $1 \times 2 \times 5 \times 3$ me sale: - el vacío es triste? ¿Qué significa?

$1^{\circ}$ Una base: artículo+sujeto+verbo+adjetivo.

$2^{\circ}$ La realidad del valor configurado

Si lo relativo es absoluto evita dar soluciones mecánicas. (...)

En Monte de goce, extensas notas con comentarios, análisis y explicaciones que "traducen" en términos técnicos (fórmulas, esquemas, dibujos) algunas de las complejas imágenes eróticas de los poemas. En "Arte poética a propósito del libro Monte de goce", Verástegui señala en relación con su proyecto de escritura:

Yo solamente he sido un filmador de la crudeza diaria que experimenta y vive el hombre y la mujer de la urbe de nuestro tiempo. En este sentido Monte de goce no es un libro de poemas, es mejor la escritura continua a través de la cual pasan los géneros literarios: narraciones, sonetos, formas teatrales, guión de cine; sí, claro, hay eso: un flujo de conciencia (como en Joyce), hay también esquemas matemáticos que provienen de mi vinculación con los estudios de economía que hice en San Marcos. La significación de tales combinaciones o permutaciones obedece a mi deseo de representar la variación de los cuerpos en el lecho amatorio (1991: 8).

La propuesta de Verástegui a no dudar da cuenta de uno de los más complejos intentos de "mutaciones" disciplinarias que ofrece la poesía hispanoamericana de nuestro tiempo y uno de los resultados del regreso a la poesía hispanoamericana de las poéticas neovanguardistas, lejanas de las poéticas del silencio y la brevedad, del minimalismo contemplativo de buena parte de la poesía anterior.

2. La historia de la poesía chilena a partir de los años 70 está marcada por dos hechos históricos extremos: la asunción de Salvador Allende al Gobierno en el año 1970 y el golpe de Estado de 1973. Sin embargo, la resituación de los códigos comunicativos en la poesía es un proceso que sintomatiza también estos conflictos 
históricos. Se trata de un repertorio marcado por la búsqueda de nuevas posibilidades comunicativas ${ }^{5}$, caracterizadas por hibridación, la mutación y la pluralidad inestable. Grinor Rojo (1989: 53-76) ha demostrado que la irrupción de una poesía vanguardista y experimental aparece tímidamente poco antes del golpe del 73. El año 1972 se publica en Buenos Aires la antología Nueva poesía joven de Chile de Martín Micharvegas donde se incluyen textos de Juan Luis Martínez y Raúl Zurita. Sin embargo, en el campo literario chileno la irrupción neovanguardista se produce a partir de $1977^{6}$, con la publicación de La Nueva Novela 7 y La poesía chilena (1978) de Juan Luis Martínez (1942-93), Purgatorio (1979) ${ }^{8}$ de Raúl Zurita y la aparición de CADA, Colectivo de Acciones de Arte, este mismo año.

Juan Luis Martínez constituye en la actualidad una de las principales referencias, si no la más importante, de este proceso de renovación escritural. La nueva novela es un microtexto que articula diversos soportes: lingüístico, visual y objetual, por medio de la incorporación de textos, dibujos y eventualmente objetos que construyen el texto como una unidad semiótica plural y abierta a la intervención del lector. Bernardo Subercaseaux explica en los siguientes términos la propuesta del texto:

Se trata de un palimpsesto de discursos culturales en que todo anverso tiene su reverso, un pastiche escritural y visual en que se da un juego permanente de construcción y deconstrucción, un ludismo en que el sentido último permanece en suspenso. No hay en esta obra un sujeto concéntrico de referencia: el gesto del autor es tacharse a sí mismo y ofrecer en cambio una hibridación diacrónica de distintas escrituras, aludiendo así a la imposibilidad de una instancia totalizadora y omnicomprensiva. (1990: 137)

Uno de los elementos que ha llamado la atención de la crítica es su voluntad de negar la relación texto-autor. El signo más evidente de este intento está dado por la tachadura del nombre como indicador autorial (JUAN LUIS MARTINEZ) y su reemplazo por el de (JUAN DE DIOS MARTINEZ) también tachado y nuevamente entre paréntesis. Este elemento ha sido recogido como indicador del afán por disolver la figura del autor en el contexto de la búsqueda de su negación. En una entrevista a María Ester Roblero Martínez señala: "Me complace irradiar una identidad velada

\footnotetext{
5 Rodrigo Cánovas ha planteado que en Chile la interrupción del diálogo social provocada por el golpe de Estado genera en los primeros años de dictadura una afasia colectiva: "A nivel cultural, la afasia implica un habla que no dice nada, un tejido amorfo de significados que equivale a lo que en lingüística se denomina simplemente 'ruido'. Además de constituir un síntoma de la pérdida de referentes de una comunidad (se cuenta con discursos ideológicos absolutamente ineficaces para explicar una situación histórica nueva), este lenguaje dislocado es el efecto de una censura disgregadora, que la comunidad ha internalizado (el miedo paraliza la libre expresión de las ideas, haciéndolas enrevesadas y casi ininteligibles)" (1986: 131). Para Eugenia Brito, "La nueva escritura exhibirá hasta la exageración ese carácter opresivo, victimario y reductor del sistema dominante, transgrediendo sus leyes e intentando liberar ese cuerpo ocupado" (1994: 11).

${ }^{6}$ Fundamentales en la reflexión sobre arte conceptual y poesía han sido Ronald Kay, junto a Eugenio Dittborn y Catalina Parra, con el grupo VISUAL (1977). A esas alturas ya teníamos los Artefactos (1971) de Nicanor Parra. A partir de los años 80 Enrique Lihn trabaja en la incorporación de fotografías, plástica y videos a sus creaciones artísticas. En la plástica, Leppe, Altamirano y Smythe utilizan fotografías, textos y objetos en la elaboración de sus cuadros conceptuales.

7 Una primera versión de La nueva novela fue entregada a Editorial Universitaria de Valparaíso en 1971, sin llegar a publicarse, al parecer bajo el título de Pequeña cosmogonía práctica.

8 Además de los textos incluidos en la antología de Martín Micharvegas, en 1975 la revista Manuscritos publica con el título de "Un matrimonio en el campo" la sección "Areas verdes" de Purgatorio.
} 
como poeta; esa noción de existir y no existir, de ser más literario que real. De joven leí un aforismo de Novalis: 'La poesía es lo real absoluto'. Si entonces me sedujo esa afirmación, hoy estoy convencido de que es asî́" (1993: 4). La tachadura del autor que, en rigor, constituye un intento por situar una nueva figura autorial, encuentra además su expresión en los diversos juegos de intertextualidad que el autor propone de tal manera que la escritura se convierte en un espacio de juego y de permanentes alusiones a diversos textos de la tradición literaria y cultural. Este sistema citacional implica una versión paródica de la tradición de la "obra total", en la medida en que el libro resulta ser un bricollage de citas efectivas y alusiones cifradas que por un lado obstaculizan la recepción y por otro lo convierten en una obra abierta. Sin embargo, creo que más allá de esta voluntad detrás de la negación del autor se encuentra como es frecuente en estos casos una verdadera fijación: la obsesión por el nombre. La tachadura del nombre resulta un elemento más del juego de relaciones del texto, convierte a este nombre y a su alter ego (Juan de Dios Martínez) en personajes del texto.

Raúl Zurita (1950) es otro intento de superación de la noción de texto e incluso de objeto artístico, al incorporar el espacio del cuerpo y la realidad como soportes de la escritura. Por una parte ha explorado en las posibilidades traumáticas del dolor para metaforizar en su propio cuerpo las agresiones sufridas por el cuerpo social (la imagen de su cara quemada sirve de portada para la primera edición de Purgatorio (1979); el relato de un intento de cegadura cierra Anteparaíso (1982). La segunda vía es la ampliación del soporte textual a la realidad misma. Las iniciativas quedan nuevamente como huellas en sus textos. La escritura con humo de aviones de un poema en el firmamento de Nueva York, cuyas fotografías se reproducen en Anteparaíso, o la escritura por medio de retroexcavadoras de un verso legible sólo desde las alturas ("NI PENA NI MIEDO") sobre el desierto de Atacama, que cierra La vida nueva (1994).

Es interesante que el desarrollo asimétrico y no homogéneo de la poesía de los 60 explica el proceso de transformaciones que sufre la poesía chilena a partir de los 70 . Se trata de un proceso que dotó de sentido las nuevas prácticas escriturales por la vía de la elusión y lo no dicho, pero que también sirvieron para hacer visibles dinámicas escriturales desconocidas hasta entonces. Hacia finales de los 70 y principios de los 80 se hace evidente la consolidación de diversas modalidades de rearticulación. Una de las expresiones más interesantes es el surgimiento en el año 1979 del Colectivo de Acciones de Arte (CADA), formado por el sociólogo Fernando Balcells, la escritora Diamela Eltit, el poeta Raúl Zurita y los artistas visuales Lotty Rosenfeld y Juan Castillo. Se trata de una agrupación neovanguardista de gran impacto, tanto por la relevancia de los artistas que se vincularon a ella como por la singularidad de sus "acciones de arte", tendientes a reestablecer las relaciones entre literatura y vida. Nelly Richard (1994) ha situado la radicalidad de CADA y su proyecto por alcanzar la fusión "arte/ vida" y "arte/política" en el contexto de la "escena de avanzada". En su momento habrá que considerar de qué manera estas iniciativas permitieron un interesante flujo que pasó a formar parte del rescate del discurso propagandístico de la oposición política. Entre las acciones de arte más relevantes de CADA fueron "Para no morir de hambre en el arte", "Inversión de escena", "Ay, Sudamérica", "Residuos americanos", "NO +" y "Viuda". Cada una de estas acciones se encuentra descrita por Robert Neustadt en Cada día: la creación de un arte social (2001). "Ay, Sudamérica" (1981), una de las políticamente más significativas, consistió en el planfleteo de 400.000 volantes en diversos sectores de Santiago, además de la publicación en medios alternativos de 
un texto llamando a la ruptura de la distinción entre trabajo manual y trabajo intelectual. Este texto se convierte en un auténtico manifiesto del colectivo que resitúa, como ocurrió en Perú con Hora Zero, el rol y la función del arte y la poesía. Por su relevancia me permito una cita más extensa de lo habitual:

Nosotros somos artistas, pero cada hombre que trabaja por la ampliación, aunque sea mental, de sus espacios de vida es un artista.

Lo que significa que digamos el trabajo en la vida como única forma creativa y que digamos, como artistas, no a la ficción en la ficción.

Decimos por lo tanto que el trabajo de ampliación de los niveles habituales de vida es el único montaje de arte válido / la única exposición / la única obra de arte que vive.

Nosotros somos artistas y nos sentimos participando de las grandes aspiraciones de todo, presumiendo hoy con amor sudamericano el deslizarse de sus ojos sobre estas líneas.

Ay, Sudamérica.

Así conjuntamente construimos el inicio de la obra: un reconocimiento en nuestras mentes; borrando los oficios: la vida como acto creativo.

Ese es el arte / la obra / este es el trabajo de arte que proponemos (julio 1981)

Frente al minimalismo y al conceptualismo, la neovanguardia chilena optó por la radicalización política del arte, lo que condujo finalmente a una propuesta positiva, solidaria y humanista en algunos de sus representantes, de los que Zurita es el mejor y mayor ejemplo. Nelly Richard (1994) ha destacado las contradicciones que se vivían en los proyectos que habitaban las acciones de la "escena de avanzada": la contradicción entre el utopismo mesiánico de la vanguardia y el arte de situación; la síntesis integradora y cohesionadora del Todo, ante la erraticidad del fragmento; en fin, el rupturismo de la vanguardia utópica revolucionaria ante el deconstructivismo crítico de un arte postvanguardista.

El proceso es evidentemente más amplio, pues afecta también otros modos de poetizar, suponen una ampliación de la noción de libro como espacio de codificación abierto, de relativización de la noción de poema como unidad, de exploración en un sujeto escindido que pugna por su reaparición y de indagación en el lenguaje y la historia como espacios de control. Como ejemplos de estas escrituras renovadoras se puede mencionar la producción de Diego Maquieira con una de las publicaciones clave del período, La Tirana (1983); Gonzalo Muñoz: Exit (1983); Tomás Harris: Zonas de peligro (1985), Diario de navegación (1986) y El último viaje (1987), libros reunidos en Cipango (1992); Carmen Berenguer: Bobby Sand desfallece en el muro (1983), Huellas de Siglo (1986), A Media asta (1988), Sayal de pieles (1993), Naciste Pintada (1999) y La gran hablada (2002); Juan Cameron: Cámara oscura (1985), Video Clip (1989); Rodrigo Lira: Proyecto de obras completas (edición póstuma, 1984); Alexis Figueroa: Virgenes del sol in cabaret. Vienbenidos a la máquina. Welcome to the TV (1986); Jorge Torres: Poemas encontrados y otros pre-textos (1991); Eugenia Brito: Vía pública (1984); Elvira Hernández: La bandera de Chile (1991); entre otros. Las ciudades en que emergen estas prácticas y se articulan grupos, revistas y editoriales 
autogestionadas son Valdivia, Concepción, Valparaíso y Santiago, preferentemente. Las indagaciones en los espacios poblacionales y barriales es la apuesta de José Angel Cuevas, uno de los autores más significativos del período, que comienza a publicar de modo sistemático en el año 1979 y que reúne parte importante de sus trabajos en Adiós muchedumbres (1989). Este modo de producción que se proyecta a sus libros posteriores Treinta poemas del ex-poeta José Angel Cuevas (1992), Proyecto de País (1994) y Poesía de la comisión liquidadora (1997) supone una lectura política de los complejos procesos de la transición democrática?

Los elementos más renovadores de la poesía del período se encuentran definidos por la búsqueda de la superación del poema como unidad textual, para dar lugar a la noción de libro como obra abierta hacia la realidad y la vida; el conceptualismo puro no tiene lugar en el espacio de una escritura fuertemente marcada por el gesto testimonial y político. Dos obsesiones la atraviesan. La primera es la idea política de patria. Chile es un motivo explícito hasta el cansancio. De esta obsesión no escapa Martínez con sus banderitas chilenas en sus dos libros, ni Zurita en Anteparaíso (1982) y La vida nиеva (1994) y es fundamental en el trabajo de José Angel Cuevas, Elvira Hernández, Tomás Harris o Carmen Berenguer. La segunda, el estatuto de un sujeto escindido y múltiple: Juan de Dios Martínez el alter ego de Juan Luis Martínez; "Raúl”/“Raquel" en Raúl Zurita; "la tirana" y los múltiples hablantes de Diego Maquieira; los personajes "asqueados o ebrios" (Efrén L. Sepúlveda Fica, Mario Manguncia, Tito Alvarado Gil) de José Angel Cuevas. Eugenia Brito (1994) ha destacado la frecuencia con que estos personajes además semiotizan en femenino, aunque a veces sus autores sean masculinos. Se trata de una metáfora de la cultura de la violencia, presente en ese híbrido lírico-narrativo que es Lumpérica (1983) de Diamela Eltit; o en La bandera de Chile de Elvira Hernández; o en Huellas de siglo (1986) y A media asta (1988) de Carmen Berenguer.

3. La poesía argentina a partir de los años 70 está marcada por el golpe de Estado de marzo de 1976. Como en Chile en Perú, se radicaliza la desconfianza en el lenguaje, en la historia, en la cultura. Andrés Avellaneda (1984) plantea certeramente que la poesía de los 70 reemplaza la creencia en la identidad entre poesía y lenguaje conversacional, por la premisa de que existe un conflicto entre ambos lenguajes. Se trata, en su opinión, de una escritura que puso toda su confianza en el efecto estético que nace de la resistencia entre el material lingüístico y la búsqueda realizada con el instrumento poético. Esta reflexión y tensión es la que provoca la reaparición de un tono neovanguardista, caracterizada por la opacidad, lo no dicho, la simulación como estrategia textual. Es precisamente este conflicto entre lenguaje y realidad, entre poesía e historia el que provoca a nivel latinoamericano un esfuerzo por reflexionar en las fracturas históricas provocadas por la irrupción de las más radicales formas de autoritarismo que había conocido el siglo XX.

Para el poeta y crítico Daniel Friedemberg (1984) el rasgo distintivo del período es el surgimiento hacia 1974 de una postura neorromántica, reactiva contra el coloquialismo,

\footnotetext{
9 Agreguemos todavía que la exploración experimental en los espacios marginales de las urbes latinoamericanas es parte de un modo de producción de la poesía chilena del período y se constituye en una característica clave de los poetas de finales de los 80 y principios de los 90: Guillermo Valenzuela (Fabla Graffity, 1987), Sergio Parra (La manoseada, 1987), Malú Urriola (Piedras rodantes, 1988), Víctor Hugo Díaz (Doble vida, 1989).
} 
aunque el gesto, de hecho, también desafía a las vanguardias 'cincuentistas', al restaurar el arsenal retórico que éstas querían abolir. Los principales exponentes de esta perspectiva se agrupan en torno al grupo Nosferatu (liderado por Mario Morales), el que será continuado en los años siguientes por la revista Ultimo Reino, dirigida por Gustavo Magulies y Víctor Redondo ${ }^{10}$. Será este gusto por lo oscuro, el esteticismo y la inasibilidad de los significados la fascinación por el lenguaje sometido a fuertes tensiones de significación, lo que dará lugar a la denominación de una "poesía argentina barroca" por parte del poeta Jorge Ricardo Aulicino.

La revista publicada en Rosario El Lagrimal Trifulca de carácter antipoético (Francisco y Elvio Gandolfo, Hugo Diz, Eduardo D’Anna, Sergio Kern); el neoconcretismo de Nahuel Santana; el objetivismo de Raúl García Brarda y Rafael Felipe Oteriño; el intelectualismo de Marcelo Moreno y Pablo Ananía, entre otros, descritos también por Friedemberg y repasados por Fonderbrider son otros polos que caracterizan la heterogeneidad del período. Para Fonderbrider (2006: 20) "Incertidumbre, desconfianza, abordaje oblicuo del discurso, enmascaramiento, fractura, desplazamiento de los grandes temas a la propia subjetividad, búsqueda de un centro ubicado fuera del entorno social inmediato" son términos recurrentes utilizados por la crítica para identificar estos años de transición que, "ahora, con la mediación del tiempo, bien pueden servir para reflejar el ánimo de parte de la sociedad argentina durante los años de dictadura".

A fines de los 70 aparece el primer número (1979) de la revista Ultimo Reino, fusión de Nosferatu y El sonido y la furia de Víctor Redondo, Susana Villalba y Mónica Tracey, entre otros. La historia posterior es conocida; un año después se publica Xul. Signo viejo y nuevo dirigida por Jorge Santiago Perednik, Nahuel Santana, Emeterio Cerro, Arturo Carrera y Néstor Perlongher. En 1981 Jonio González y Javier Cófredes publicaron el primer número de La Danza del Ratón, distantes de la poética neorromántica comienzan a perfilar una poética "objetivista". Postestructuralista y neobarroca fue la revista Sitio que publicó siete números entre 1981 y 1987. Heredera de Literal (1973-1977), su núcleo estaba constituido por Ramón Alcalde, Jorge Jinkis y Luis Thonis. Entre sus colaboradores se cuentan autores de distintas generaciones marcados por las preocupaciones teóricas reconstructivas: Leonidas Lamborghini, Osvaldo Lamborghini, Silvia Molloy, Enrique Pezzoni y, por supuesto, Néstor Perlongher (Martínez Cabrera 2008). Considerando el rol que juegan las revistas literarias, nada hemos dicho sobre el Diario de Poesía que se comenzó a publicar en 1986, fundado y dirigido por Daniel Samoilovich.

Así en los 80 se organizaron distintos grupos: los neobarrocos (Arturo Carrera, Tamara Kamenszain, Héctor Piccoli) o neobarrosos (denominación de su mayor héroe, Néstor Perlongher), los objetivistas (Martín Prieto, Daniel García Helder), los neorrománticos (Jorge Santiago Perednik) y los concretistas $(X u l)$. La poesía visual tuvo su lugar desde mediados de los 60 con la publicación de Diagonal Cero, editada por Edgardo Antonio Vigo, hasta la aparición a mediados de los 80 del grupo Paralengua (Ricardo Castro, Roberto Cignoli, Fabio Doctorovich y Carlos Estévez) que encontraron un excelente portavoz en $\mathrm{Xul}$, dirigida también por Jorge Santiago Perednik.

\footnotetext{
${ }^{10}$ La revista, la editorial y el grupo identificado en torno al neorromanticismo estuvo integrado, además de Redondo y Magulies, por Mario Morales, Mónica Tracey, Horario Zabaljáuregui, Luis Benítez, Eduardo Alvarez Tuñón, Jorge Zunino, Guillermo Roig, Enrique Ivaldi, María Julia de Ruschi Crespo, María del Rosario Sola, Susana Villalba, Daniel Arias, entre otros.
} 
En Argentina, como en Perú (Enrique Verástegui, por ejemplo) o Chile (Tomás Harris o Diego Maquieira), existen diversos autores que pueden asimilarse al concepto de neobarroco; sin embargo, es en Argentina que puede hablarse de un movimiento renovador del concepto cubano de Lezama y Sarduy, fundado en la exploración en la heterogeneidad y la diferencia latinoamericanas, al incorporar el lenguaje barrial, popular y carnavalizador como ocurre en la obra de Perlongher. La carnavalización de la historia argentina se encuentra ejemplarmente desarrollada en el palimpsesto textual que es el "Eva Perón en la hoguera" de Leonidas Lamborghini (Partitas, 1972), construido sobre la base de citas de La razón de mi vida de Eva Perón que asoma con un sentido nuevo de carácter paródico, contradictorio y crítico.

La discusión y polémicas en torno al neobarroco argentino, revisado y cuestionado en los 90 por los objetivistas Martín Prieto y Daniel García Helder, tiene algo de caricatura maniqueísta, al atribuir a los neobarrocos/neobarrocos rasgos que no tuvieron o tuvieron parcialmente o entre otros. Fundamentales para entender este debate son los trabajos "El neobarroco en Argentina" de D. G. Helder, publicado en marzo de 1987 en Diario de Poesía, y "Poesía argentina actual: del neo-barroco al objetivismo (y más allá)" de Edgardo Dobry, publicado originalmente en Cuadernos Hispanoamericanos en junio de 1999 y que citamos ahora por la edición corregida en el año 2001 (reproducida en Fonderbrider 2006). Helder señala que en las páginas de Carrera y Piccoli "El gusto por lo frívolo exótico, recargado, la ornamentación, las descripciones exuberantes o la exhuberancia, el cromatismo, las transcripciones pictóricas, las citas y alusiones culteranas, etcétera, son rasgos neobarrocos que esbozan la reapertura de algo que parecía definitivamente extinguido: el modernismo, la tradición rubendariana de Azul y Prosas Profanas, no la que se inicia con Cantos de vida y esperanza." En su alegato "contra el neobarroco" Dobry señala que buena parte de la poesía que se escribió en Hispanoamérica en los años 80 participaba de la mallarmeana alegría del poeta por haber inventado una palabra, más juego que significado, espejismo de las palabras:

De modo que es muy difícil no pensar en la poesía argentina de los noventa como una reacción contra esa estética: se huye del neologismo culto hasta llegar al territorio opuesto, el de la lengua coloquial, al habla de la calle, al argot; y se tiende a formas bastardas, cercanas al slogan publicitario o a la canción popular. Si la poesía contemporánea que desciende de Mallarmé busca la esencia de la forma para salvar a la palabra de su devaluado uso cotidiano, los poetas argentinos de los noventa, en el extremo opuesto, prefieren escribir una poesía en sí misma devaluada. Su material será una palabra abiertamente desgastada: no el oro, sino el níquel de cantos carcomidos (Dobry 2006: 121).

Resulta difícil atribuir muchos de estos rasgos a los espacios mitificados de la infancia en Arturo Carrera ${ }^{11}$ o a Néstor Perlongher ${ }^{12}$ del que el mismo Dobry señala

\footnotetext{
11 "Arturo Carrera nació el 27 de marzo de 1948, autor de una amplia obra en que se unen el gesto vanguardista a la mitificación de los espacios de la infancia y de una personal autobiografía lírica. Entre sus títulos se cuentan Escrito con un nictógrafo (1972), Momento de simetría (1973), Oro (1975), La partera canta (1982), Arturo y yo (1983), Mi padre (1985), Animaciones suspendidas (1986), La banda oscura de Alejandro (1994), El vespertillo de las parcas (1997), Tratado de las sensaciones (2001), Noche y día (2005), La inocencia (2006).

12 Néstor Perlongher publicó, además de diversos ensayos, los siguientes libros de poemas: AustriaHungría (1980), Alambres (1987), Hule (1989), Parque Lezama (1990), Aguas aéreas (1990), El cuento de las iluminaciones (1992), que se encuentran reunidos en Poemas completos (1997).
} 
que "escribió en una lengua en la que el vocabulario culto, de resonancias gongorinas, se carnavaliza con términos domésticos, barriales, y se deja contaminar por el portugués (por el portuñol como lo llamaba él)" (2006: 127). Tal vez por ello Eduardo Milán al referirse al neobarroco como un movimiento amplio y no excluyente se refiere a "La sustitución de ese neobarroco de honda prosapia histórica, transculturizado y encarnado en nuestras regiones por un más humilde, humorístico -en su nombramiento-neobarroso propuesto por Néstor Perlongher (1949-1992) es lo que permite considerar, paradójicamente, a esta emergencia poética con seriedad" (2007: 21).

El poemario Escrito con un nictógrafo (1972) de Arturo Carrera es ejemplo de reemergencia neovanguardista en la Argentina de principios de los 70. El título alude al instrumento creado por Lewis Carroll en Alicia en el País de las Maravillas para escribir el insomnio, en la oscuridad. Más allá de la dimensión autobiográfica, ya que Carrera en diversas ocasiones ha destacado que parte del texto se escribió en la noche, a oscuras, la visualidad del texto alude a la relación oscuridad/luz, noche/día. Escritura en blanco, sobre riguroso fondo negro, el metapoema reflexiona sobre la desaparición del poeta: "el escriba ha desaparecido", dice el primer verso, y la muerte también autobiográfica de su abuela: "Señalo el sitio vacío/ donde los muertos se divierten". Diversas estrofas se encuentran tachadas con una gran equis, representación de la pérdida; pero también subrayado que destaca la presencia de esa ausencia. Nancy Fernández ha destacado que Escrito con un nictógrafo sostiene y anticipa los principios neobarrocos de la escritura de Carrera, texto en el que recupera "el espacio de un lenguaje que estalla en palabras e imágenes de caos y vacío”, página insomne y noctámbula que "da forma a una escritura quiasmática que hace indiscernible el punto de origen o la regulación de un centro ontológico (2008:23): "Yo hablo escribiendo / no marco ningún lugar / no puedo volver ya más/ a ningún lugar". Este texto anticipa Momento de simetría (1973) y Oro (1975); así como su obra posterior en que construye una original autobiografía poética que reprocesa y amplía los registros de la escritura neobarroca por medio de complejas aliteraciones verbales.

La escritura de Néstor Perlongher implica poner en tensión las posibilidades mismas de la poética neobarroca por medio de un gesto urbano, testimonial y, permítanme el oxímoron, muchas veces fuertemente realista. Wasen recuerda que para Perlongher el barroco es un arte antioccidental "ya que opera mezclas transculturales" (2008: 39). El ya tantas veces citado poema "Cadáveres" de Perlongher incluido en Alambres es la mejor expresión de la dimensión política, testimonial que puede alcanzar su escritura y un verdadero manifiesto político-poético del período. El poema comienza con una explícita referencia a los ejecutados y desaparecidos de la dictadura militar: "Bajo las matas / En los pajonales / Sobre los puentes / En los canales / Hay Cadáveres”. Para continuar en una progresiva saturación verbal neobarrosa que no puede sino culminar en los puntos suspensivos de una poética del silencio, del espanto:

En el tepado de la que se despelmaza, febrilmente, en la menea de la que se lagarta en esa yedra, inerme en el despanzurrar de la que no se abriga, apenas, sino con un saquito, y en potiche de saquitos, y figurines anteriores, modas pasadas como mejas muertas de las que Hay Cadáveres 
Se ven, se los despanza divisantes flotando en el pantano:

en la colilla de los pantalones que se enchastran, símilmente;

en el ribete de la cola del tapado de seda de la novia, que no se casa

porque su novio ha

Hay Cadáveres

\section{PARA CONCLUIR}

Los años 70 se abren, en el contexto hispanoamericano del cono sur, a una abierta tendencia a la exploración neovanguardista, a la resituación de claves expresivas que recuerdan el gesto rupturista y vital de las primeras vanguardias. Se trata de un vanguardismo cuyas fuentes son más angloamericanas que francesas y que, por lo mismo, incorpora frecuentemente el uso del lenguaje conversacional, en su versión popular y barrial. Más explícitamente políticas, las poéticas dominantes en Chile y Perú se articulan con evidentes similitudes, frente a un sistema poético como el argentino que incorpora la tradición romántica y neorromántica. La tensión entre los lenguajes permite diversos tipos de mutaciones y migraciones genéricas y disciplinarias, provocando un tipo de escritura caracterizado por la heterogeneidad, el relativismo y una textualidad tensionada que no llega a sintetizar los distintos tipos de discursos en juego. La pluralidad semiótica es otro rasgo relevante. Los textos incorporan no sólo los discursos que provienen de otras disciplinas artísticas, sino también de otras disciplinas y saberes, hibridándose e injertándose en un macrotexto complejo de múltiples referencias culturales desjerarquizadas. El sujeto, por otra parte, muestra las complejidades de una relación no resuelta entre lenguaje y representación. Por ello son frecuentes textos polifónicos con presencia de múltiples sujetos distorsionados, carentes de centros de referencia, tras la búsqueda de una comunicación imposible. La poesía así aparece como el espacio de resistencia, de verbalización, en medio de contextos represivos o tensionales. El cuerpo social para el que se escribe se escabulle. Las nuevas vanguardias una vez más muestran su inevitable gesto político, su capacidad para resituar las posibilidades comunicacionales y de representación de la escritura.

\section{OBRAS CITADAS}

Andrés, Alfredo. 1969. El 60. Buenos Aires. Editores Dos.

Avellaneda, Andrés. 1984. "Poesía argentina del 70". Dossier "10 años de poesía argentina". La danza del Ratón. Buenos Aires, Año IV, $\mathrm{N}^{\circ} 6$, diciembre.

Bürger, Peter. 1987. Teoría de la vanguardia. Barcelona. Península.

Brito, Eugenia. 1994. Campos minados (Literatura post-golpe en Chile). Santiago de Chile. Cuarto Propio.

Calinescu, Matei. 2002. Cinco caras de la modernidad: modernismo, vanguardia, decadencia, kitsch, postmodernismo. Madrid. Tecnos.

Cánovas, Rodrigo. 1986. Lihn, Zurita, ICTUS, Radrigán: literatura chilena y experiencia autoritaria. Santiago de Chile. FLACSO. 
Carrasco, Iván. 2002. "Interdisciplinariedad, interculturalidad y canon en la poesía chilena e hispanoamericana actual”. Estudios Filológicos 37: 199-210.

Ceballos Mesones, Leonidas. 1967. Los nuevos. Cisneros / Henderson / Hinostroza / Lauer / Martos / Ortega. Lima. Universitaria.

De Lima, Paolo. 2005. 'La Universidad de San Marcos, la Revolución y la 'involución' ideológica del Movimiento 'Hora Zero'. A veinticinco años de 'Palabras urgentes (2)' de Juan Ramírez Ruiz", en Ciberayllu [en línea], 16 de febrero del 2009.

Dobry, Edgardo. 2006. "Poesía argentina actual: del neo-barroco al objetivismo (y más allá)". Tres décadas de poesía argentina 1976-2006. Jorge Fonderbrider (ed.). Buenos Aires. Libros del Rojas.

Fernández, Nancy. 2008. Experiencia y escritura. Sobre la poesía de Arturo Carrera. Buenos Aires. Beatriz Viterbo Editora.

Friedemberg, Daniel. 1984. "Para una situación de la poesía argentina", dossier "10 años de poesía argentina". La Danza del Ratón. Buenos Aires, Año IV, $\mathrm{N}^{\circ}$ 6, diciembre.

—. 1999. "Herencias y cortes. Poéticas de Lamborghini y Gelman". Historia crítica de la literatura argentina. Noe Jitrik (director). Vol. 10. Susana Cella, directora del volumen. Buenos Aires. EMECE.

Fonderbrider, Jorge. 2006. "Treinta años de poesía argentina”. Tres décadas de poesía argentina 1976-2006. Buenos Aires. Libros del Rojas.

- 2008. Una antología de la poesía argentina. 1970-2008. Santiago de Chile. LOM.

Galindo, Oscar. 2002. "Mutaciones disciplinarias en la poesía de Enrique Lihn”. Estudios Filológicos 37: 225-240.

2004. "Interdisciplinariedades en las poesías chilena e hispanoamericana actuales". Estudios Filológicos 39: 155-165.

Helder, D. G. 1987. "El neobarroco en Argentina”. Diario de Poesía. Buenos Aires, año I, $\mathrm{N}^{\circ} 4$, marzo.

Higgins, Jaime. 1993. Hitos de la poesía peruana. Lima. Milla Batres.

Martínez Cabera, Erika. 2008. Carnaval negro: veinte poetas argentinas de los ochenta. Tesis doctoral. Universidad de Granada.

Micharvegas, Martín. 1972. Nueva poesía joven de Chile. Buenos Aires. Noé.

Milan, Eduardo. 2007. "Prólogo. Muestra de poesía latinoamericana". Pulir huesos. Veintitrés poetas latinoamericanos (1950-1965). Barcelona. Galaxia Gutenberg. 9-45.

Neustadt, Robert. 2001. Cada día: la creación de un arte social. Santiago de Chile. Cuarto Propio.

Richard, Nelly. 1994. La insubordinación de los signos: (cambio político, transformaciones culturales y poéticas de la crisis). Santiago de Chile. Cuarto Propio.

Roblero, María Ester. 1993. "Me complace irradiar una identidad velada" (entrevista con Juan Luis Martínez), Revista de Libros, El Mercurio, 14 de marzo, p. 1-4-5.

Salas, Horacio. 1975. Generación poética del 60. Buenos Aires. ECA.

Subercaseaux, Bernardo. 1990. "Nueva sensibilidad y horizonte 'post' en Chile (Aproximaciones a un registro)". Nuevo texto crítico $6.135-145$.

Toro Montalvo, César. 1991. Poesía peruana del 70. Generación vanguardista. Lima. La Tortuga Ecuestre.

Wasem, Marcos. 2008. Barroso y sublime: poética para Perlongher. Buenos Aires. Godot. 